\title{
Anti-Golgi complex antibodies during pegylated-interferon therapy for hepatitis $\mathrm{C}$
}

Paraná R, Schinoni MI, de Freitas LAR, Codes L, Cruz M, Andrade Z, Trepo C. Anti-Golgi complex antibodies during pegylated interferon therapy for hepatitis $\mathrm{C}$.

Liver International 2006: 26: 1148-1154.

(C) 2006 The Authors. Journal compilation (C) 2006 Blackwell Munksgaard

Abstract: Background/Aim: Pegylated interferon (Peg-IFN) plus ribavirin is the standard therapy for hepatitis C. Peg-IFN has several antiviral mechanisms, but its role in hepatitis $\mathrm{C}$ treatment seems to be related to its immunomodulatory effect. Ribavirin, an antiviral agent, potentiates IFN activity when added to it. Both drugs are associated with adverse reactions of different magnitudes. Autoimmune phenomena have been reported with this treatment. In this paper, we describe cases of ALT/GGT flares during PegIFN plus ribavirin treatment, which related to the appearance of anti-Golgi antibody and disease progress. Methods: We investigated three patients with hepatitis $\mathrm{C}$ and severe ALT/GGT flares during Peg-IFN and ribavirin treatment coinciding with anti-Golgi complex antibody as the only marker of autoimmunity. We then reviewed the medical files and tested anti-Golgi antibody in stored sera from 25 patients treated with conventional IFN and in 14 patients treated with Peg-IFN. Results: The three patients were male, over 45 years of age; all were relapsers and non-responders. Anti-Golgi antibody was positive during treatment coinciding with ALT/GGT flares but with hepatitis $\mathrm{C}$ virus (HCV)-RNA negativity, disappearing after stopping treatment, with normalization of ALT/AST levels. One patient had progression of fibrosis from F2 to F3 despite negativity of HCV-RNA. In the last group, only two patients treated with Peg-IFN experienced ALT/GGT flares but without anti-Golgi antibody Conclusions: The presence of antiGolgi complex antibody could be a marker of a temporary autoimmune phenomenon and progressive disease.

\section{Raymundo Paraná1, Maria Isabel Schinoni ${ }^{2}$, Luiz A. R. de Freitas ${ }^{3}$, Liana Codes ${ }^{2}$, Marla Cruz ${ }^{4}$, Zilton Andrade $^{3}$ and Christian Trepo ${ }^{5}$}

${ }^{1}$ Gastro-Hepatology Unit, Faculty of Medicine, University Hospital of Bahia, Bahia, Brazil, ${ }^{2}$ Post Graduated Program on Medicine and Health, Faculty of Medicine, Federal University of Bahia, Bahia, Brazil, ${ }^{3}$ Gonçalo Moniz Research Center, Oswaldo Cruz Foundation-Bahia, Bahia, Brazil, ${ }^{4}$ LEME Laboratory, Bahia, Brazil, ${ }^{5}$ INSERM_U 271_University Claude Bernard, Lyon, France

Pr. Raymundo Paraná, Av Juracy Magalhães Jr 2096 sala 510, Salvador-BA, Brazil 41920000.

Fax: +775134520747

e-mail: unif@svn.com.br and/or rparana@ ufba.br

Received 27 January 2006, accepted 19 July 2006
Infection with hepatitis $\mathrm{C}$ virus (HCV) is an important public health problem worldwide (1). About $55-86 \%$ of $\mathrm{HCV}$ patients develop chronic infection (2-4).

Chronic HCV is usually characterized by a lack of symptoms or only fatigue or abdominal pain. Extra hepatic manifestations are well known and primarily associated with autoimmune or lymphoproliferative states such as arthritis, autoimmune thyroiditis, diabetes mellitus, idiopathic thrombocytopenic purpura, myasthenia gravis, Sjogren syndrome, aplastic anemia, essential mixed (type II) cryoglobulinemia, monoclonal gammopathy and non-Hodking lymphoma. Dermatological manifestations include erythema multiforme, erythema nodosun, Lichen Planus, Porphyria cutanea tarda, psoriasis, pruritus and vasculitis. Idiopathic pulmonary fibrosis and membranoproliferative glomerulonephritis have also been reported (5).

Patients with chronic HCV infection do have a higher prevalence rate of autoantibodies in the serum (6). The determination of the antinuclear antibody has thus been recommended before starting HCV therapy (7).

Since 1999, interferon (IFN) plus ribavirin is considered as the standard of care for hepatitis C (8). IFN has several antiviral mechanisms, but its role in hepatitis $\mathrm{C}$ treatment seems to be related to its immunomodulatory effect (9). Despite its broad spectrum of antiviral activity, ribavirin has a negligible direct antiviral action against $\mathrm{HCV}$ replication when used in monotherapy. In contrast, it potentiates IFN activity when added to it, suggesting an additional immunomodulatory effect (10). 


\section{Anti-Golgi complex antibodies}

Both drugs are related to adverse reactions of different magnitudes. Among these sideeffects, anemia, neutropenia, thrombopenia, depression and fatigue are the most common, but less frequent adverse reactions related to autoimmune phenomena have been frequently reported.

Therapy with IFN- $\alpha$ does also induce autoantibodies in more than half of the patients treated for chronic hepatitis C. Common antibodies are antithyroid, antinuclear antibodies and antibodies against insulin. In the majority of these patients, no evidence of autoimmune disease will develop. However, in susceptible patients, autoimmune features may occur $(11,12)$.

Another unusual side-effect is autoimmune hepatitis, which can prompt immediate discontinuation of the treatment (13). Antithyroid antibodies and autoimmune thyroiditis seem to be the most common side-effects attributable to the immunomodulatory role of IFN. Autoimmune hemolytic anemia and immune-mediated thrombocytopenia purpura were related to this therapy. Autoimmune arthritis including rheumatoid arthritis can emerge during IFN- $\alpha$ therapy as well as systemic lupus erythematosus-like syndrome. Diabetes mellitus may worsen or develop during this therapy (11-16).

More recently, Pegylated interferon (Peg-IFN) replaced the conventional one because of best results in terms of sustained virological response $(17,18)$. Although these newer agents are significantly more effective than earlier versions of standard IFN, the side-effect profile of IFNbased therapies has remained unchanged despite increased incidence of AES. Thus, influenza-like symptoms (fever, myalgia and rigor) and several gastrointestinal disturbances occur with increased frequency $(P<0.05)$ in those treated with PegIFN combination therapy compared with standard IFN and ribavirine (19-21).

New side-effects of this therapy are reported continuously with the acknowledgment of the results of the different trials (22).

During Peg-IFN plus ribavirin treatment, some ALT and GGT elevations are observed, but its mechanism remains unknown (18). Such liver enzyme elevations do not seem to alter antiviral response and even mild to moderate flares are considered benign as they are not related to liver disease progression.

In this paper, we described cases of ALT/GGT flares during Peg-IFN plus ribavirin treatment, which were related to anti-Golgi antibody appearance and progressive liver disease. Interestingly, the Golgi apparatus may serve as the starting site of morphological changes associated with viral infection and replication leading to cell fusion and syncytia formation.

\section{Patients and methods}

\section{Patient 1}

A 49-year-old male patient, BMI 25, was genotype HCV 1a (INNOLIPA, Innogenetic, Belgium), treated in 1999 with conventional IFN plus ribavirin for 48 weeks. Although he responded during therapy, he relapsed within 3 months of stopping treatment. Pretreatment liver biopsy was graded A2F4 by METAVIR score. The genotype of HCV was 1a (INNOLIPA, Innogenetic, Belgium).

In 2005, he was retreated with Peg-IFN- $\alpha 2 \mathrm{a}$, once a week, plus ribavirin $1.0 \mathrm{~g} /$ day. At week 12 , he had cleared HCV-RNA (qualitative PCR, Amplicor, Roche, Basel, Switzerland). But he presented ALT flares $>10$ times the UNL. Concomitantly, GGT increased 15 times the UNL. Other causes of liver injury, such as viral hepatitis of other etiology and billiary obstruction, were ruled out. He had no symptoms, except fatigue.

He was investigated for evidence of autoimmunity with anti-TPO, ASMA and ANA, which were all found to be negative. Thyroid function tests were also normal. Autoimmunity profile was repeated and showed an immunofluorescence pattern compatible with anti-Golgi antibody in HEP cells (Fig. 1, golgi).

This autoantibody persisted during the whole treatment duration, while liver enzymes kept fluctuating from five to 10 times the UNL. Treatment was indeed maintained up to week 48, as HCV-RNA (Amplicor, Roche) was persistently negative. After stopping treatment, ALT returned to normal but GGT remained elevated

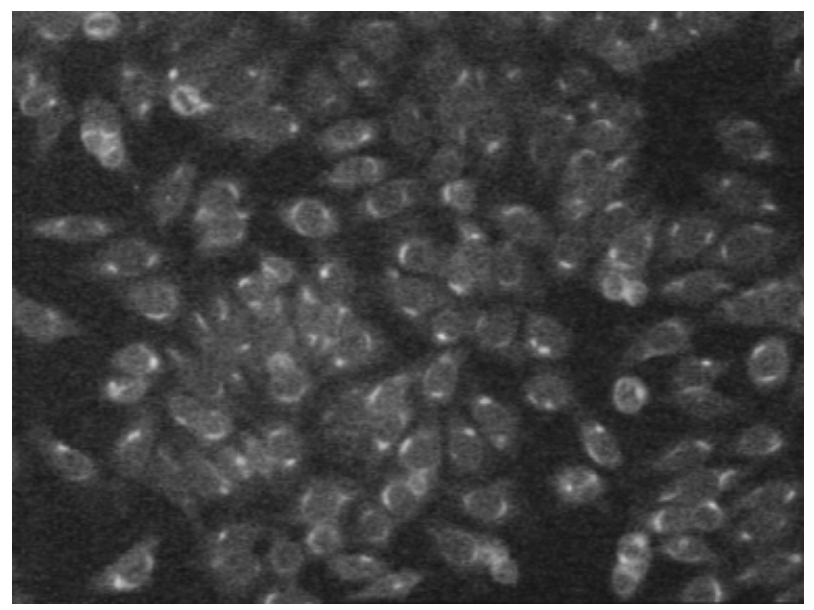

Fig. 1. Anti-Golgi complex antibody in HEP cell observed in patient 1. Similar features were also observed in patients 2 and 3 by Immunofluorescence. 
Paraná et al.

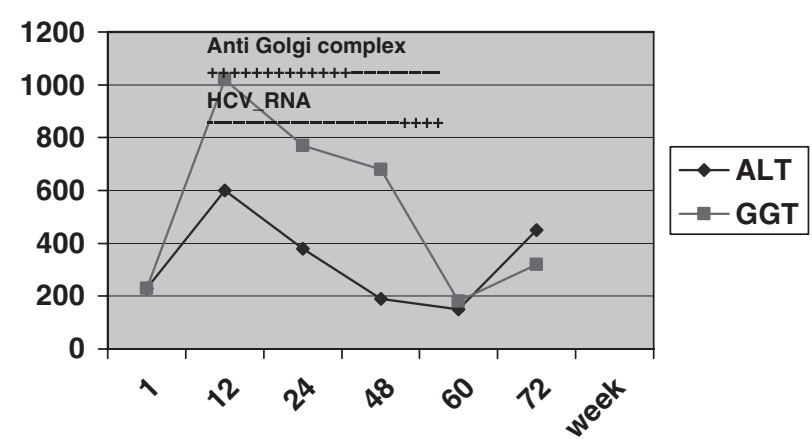

Fig. 2. Biochemical and virological follow-up of patient 1.

but less than three times the UNL. Around 3 months after stopping treatment, a new ALT flare was observed. At this time, HCV-RNA became positive, confirming a viral relapse, but no antiGolgi complex antibody was observed anymore (Fig. 2, graphic).

This patient presented no other side-effect potentially related to the antiviral treatment, except mild anemia, which did not require dose reduction of ribavirin.

\section{Patient 2}

A 52-year-old male patient, genotype HCV 1a (INOLIPA, Innogenetic) BMI 28, never treated before, initiated antiviral therapy in 2004 with Peg-IFN- $\alpha 2 \mathrm{a}$, once a week, plus ribavirin $1.0 \mathrm{~g} /$ day. Pretreatment, liver biopsy was scored A2F2 by METAVIR. Despite clearing HCV-RNA (qualitative PCR, Amplicor, Roche) at week 12, he presented ALT flare $>20$ times the UNL. Concomitantly, GGT increased 10 times the UNL. Other common causes of liver injury including basic auto-antibodies panel were ruled out as described for patient 1 . He had moderate fatigue, cough and xerophthalmia.

He was then reinvestigated again for autoimmunity with anti-TPO, anti-SSA, anti-SSB, ASMA and ANA with negative results. Thyroid function tests were normal. AMA was repeated 2 weeks later because of a mild pruritus, and examination revealed the appearance of a new immunofluorescence pattern of anti-Golgi antibody in HEP cells.

This autoantibody persisted during the whole treatment, while the liver enzymes increased to up to 30 times the UNL, and HCV-RNA (Amplicor, Roche) remained undetectable. A liver biopsy was performed during treatment (week 35) and showed evidence of necro-inflammation with fibrosis progression to $\mathrm{A} 2 \mathrm{~F} 3$ according to METAVIR (Figs 3 and 4).

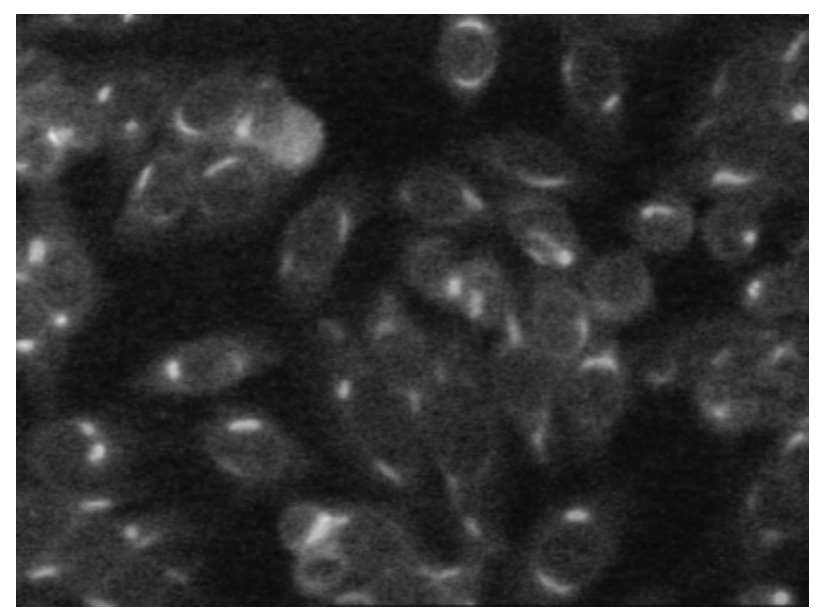

Fig. 3. Anti-Golgi complex antibody in HEP cells observed in patient 2. Immunofluorescence.
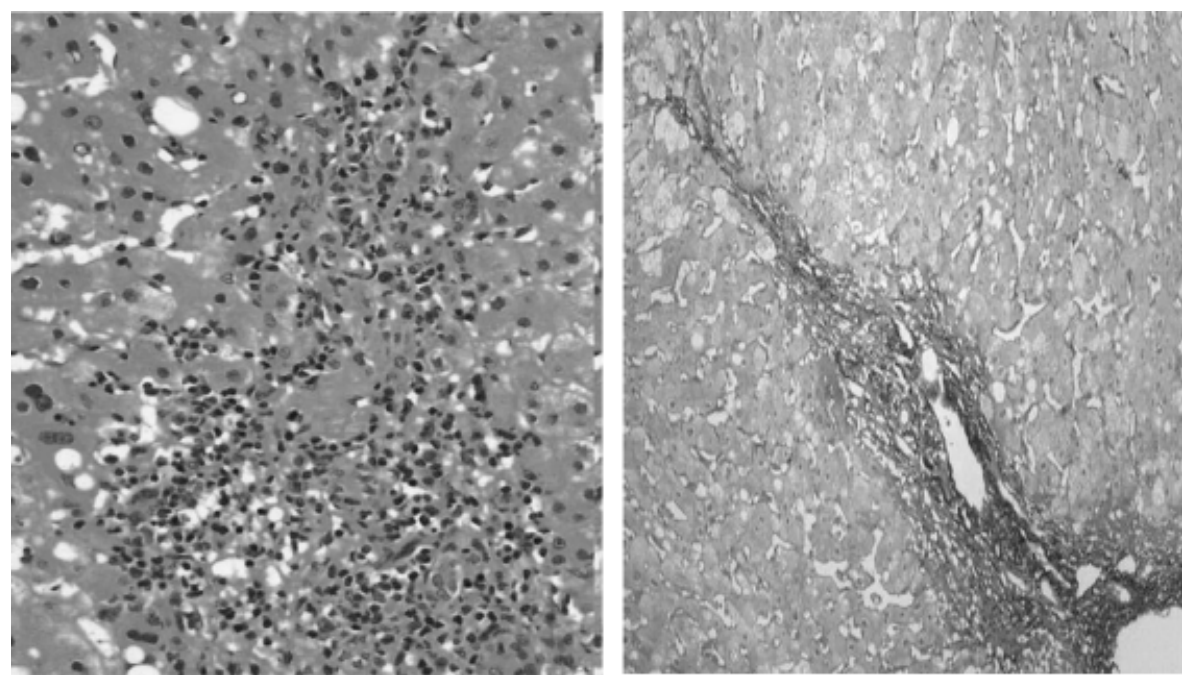

Fig. 4. Patient 2 liver biopsy before treatment showing A2F2 by Metavir score. Mild steatosis (hematoxylin-eosin and sirious red stains; original magnification $\times 40)$. 


\section{Anti-Golgi complex antibodies}
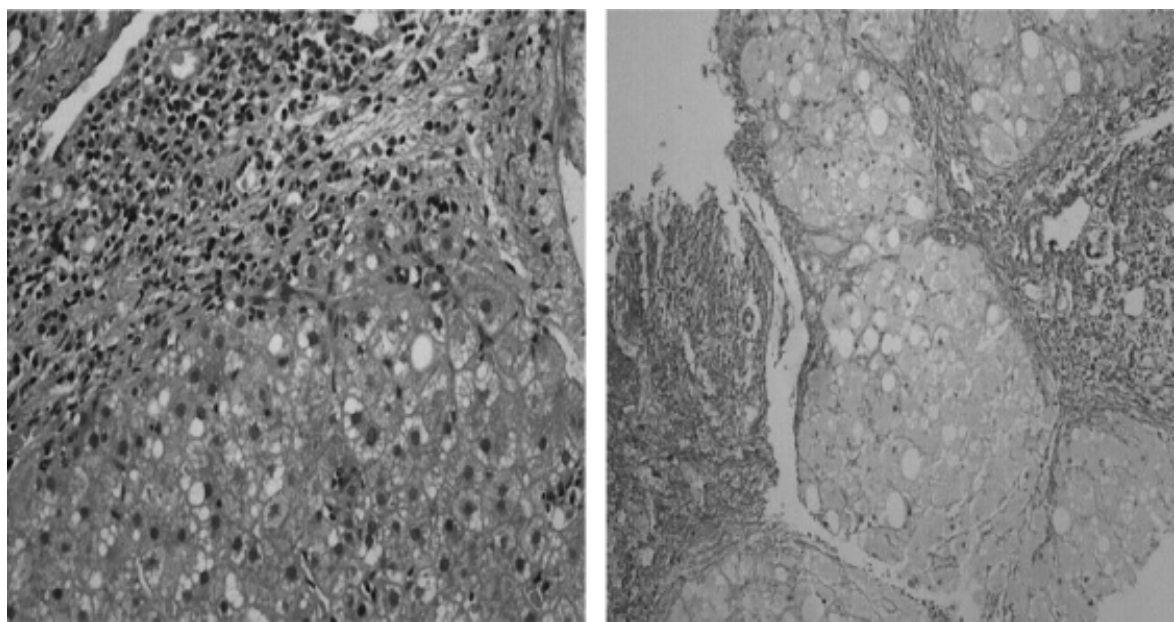

Fig. 5. Patient 3 liver biopsy during treatment showed Metavir A2 F3 regardless of undetectable HCV-RNA. Mild to moderate steatosis (hematoxylin-eosin and sirious red stains; original magnification $\times 20$ ).

The liver fragment had eight portal spaces and the second one had 12 portal spaces. The slides were revised by two experienced liver pathologists in a referral center for liver pathology.

The HCV-RNA was repeated again and remained negative. $\gamma$-globulin increased and antiGolgi complex antibody persisted. Treatment was stopped at week 36 . The liver enzymes progressively deceased to three times the UNL for ALT and five times the UNL for GGT. The anti-Golgi complex antibody disappeared after stopping treatment. Around 2 months after stopping treatment, a new ALT flare (10 times the UNL) was observed. At this time, HCV-RNA became positive, confirming a viral relapse, but no anti-Golgi complex antibody was observed anymore (Fig. 5, graphic).

This patient had no other adverse event potentially related to antiviral therapy. Mild anemia was observed but no ribavirin dose reduction was indicated. Besides fatigue, xerophthalmia, and thrombopenia, he also had transient artrhalgia with no arthritis.

\section{Patient 3}

A 62-year-old male patient, BMI 25 genotype $\mathrm{HCV}$ 1a (INOLIPA, Innogenetic), never treated before, was initiated on anti-viral treatment in 2005 with Peg-IFN- $\alpha 2$ a, once a week, plus ribavirin $1.0 \mathrm{~g} /$ day. Before treatment, liver biopsy showed A2F2 by METAVIR score.

Despite of a two-log decline in his viral load at week 12 (quantitative RT-PCR, Amplicor, Roche), he presented an ALT flare $>20$ times the UNL. Concomitantly, GGT increased 20 times the UNL. Other causes of liver injury

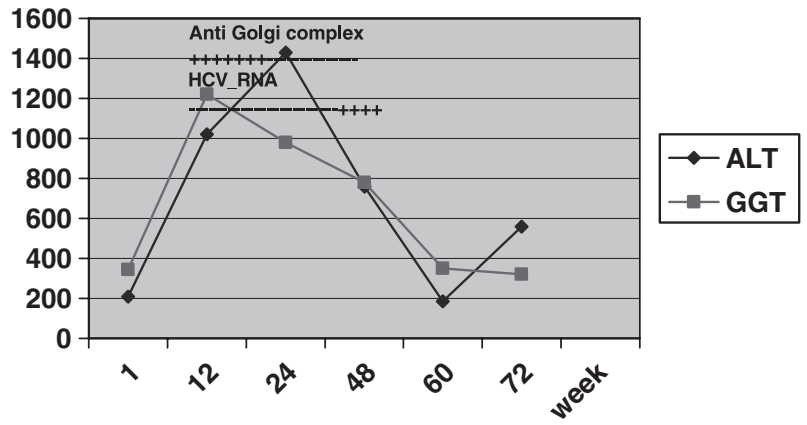

Fig. 6. Biochemical and virological follow-up of patients 2 .

were ruled out as described in patients 1 and 2 . He had fatigue and thrombopenia.

$\mathrm{He}$ was then investigated for autoimmunity with anti-TPO, ASMA and ANA, which were all negative, except for anti-Golgi complex antibody, which was positive. Thyroid function tests were normal. The patient was still viremic at week 24 and also presented neutropenia besides thrombopenia and more intense fatigue. The treatment was interrupted. After stopping treatment, liver enzymes remained silently elevated, but anti-Golgi complex antibody disappeared. Viremia persisted (Fig. 6, graphic).

Based on these results, we retrospectively reviewed the medical files and performed investigation for anti-Golgi antibody in stored sera from 25 patients treated with conventional IFN plus ribavirin, in 14 patients treated with Peg-IFN- $\alpha 2 \mathrm{a}$ and 21 patients with $\alpha 2 \mathrm{~b}$. No patient treated with conventional IFN presented mild or moderate ALT flare in these samples, but two patients treated with IFN- $\alpha 2 \mathrm{a}$ and one with $\alpha 2 \mathrm{~b}$ presented ALT and/or GGT flares from weeks 4 to 24 during treatment. In these patients liver enzymes were always below 10 times the UNL. Anti-Golgi 
Paraná et al.

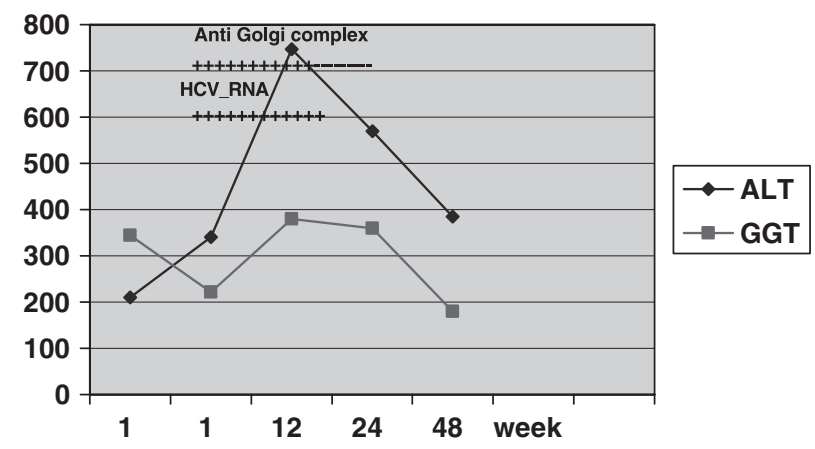

Fig. 7. Biochemical and virological follow-up of patient 3.

antibody as well as ANA and ASMA were also negative in all of them regardless of ALT/GGT flares (Fig. 7).

\section{Discussion}

In this paper, we described cases of severe ALT/ GGT flares higher than 10 ULN during Peg-IFN$\alpha 2$ a plus ribavirin treatment, which were related to anti-Golgi antibody appearance and progression of liver disease.

Anti-Golgi antibodies were first described in a patient with Sjogren syndrome and lymphoma, and were subsequently demonstrated in other clinical conditions (23).

Anti-Golgi complex antibody has been described in some autoimmune disease such as rheumatoid arthritis and systemic lupus erythematosus, but does not seem to be a specific marker so far $(24,25)$. We had observed antiGolgi complex antibodies in a few cases of cryptogenic hepatitis (data not published).

They have also been detected in malignancies. Mozo et al. (26) described the presence of high titers of anti-Golgi antibodies in a patient with virus $\mathrm{C}$-induced hepatocellular carcinoma (HCC). They found an overall frequency of anti-Golgi antibodies in their series of patients with virusinduced HCC of $5.5 \%$. The appearance of antiGolgi in these patients could be induced by the virus itself or it could be a phenomenon associated with malignant transformation and or repeated IFN therapy failures. Close follow-ups of these patients are warranted in order to screen HCC.

It was demonstrated that the Golgi apparatus may serve as the starting site of morphological changes associated with viral infection and replication, leading to cell fusion, syncitia formation and finally lysis of infected cells and virus release (27).

The ALT/GGT elevations during Peg-IFN plus ribavirin treatment have no explanation, but are generally considered a nonhazardous phenomenon, as mentioned before, especially as most of the time they are mild $<10$ ULN.

In contrast, the ALT flare during IFN treatment for hepatitis B is related to the host stimulation of the immune system, which makes these phenomena a predictive marker of sustained response (28).

These ALT elevations are more commonly reported with Peg-IFN- $\alpha 2 \mathrm{a}$ compared with $\alpha 2 \mathrm{~b}$. This may raise questions regarding a possible hepatotoxicity of $40 \mathrm{kDa}$ Peg-IFN, as it is almost completely metabolized by the liver (29).

A more likely explanation in our cases is autoimmunization triggered by IFN therapy. Hashimoto thyroditis, autoimmune hepatitis, celiac disease and many other autoimmune diseases have been described during IFN $(13,14,30,31)$. Among all described autoimmune diseases exacerbated or promoted by IFN therapy, autoimmune hepatitis is rarely described.

In these presented cases, we observed severe ALT flares together with even worse elevations of $1 \alpha$ to $20 \mathrm{ULN}$ of GGT. All patients were male, over 45 years of age and all were relapsers or nonresponders to a previous course of treatment. Anti-Golgi complex antibody disappeared after stopping treatment and no other autoimmunity marker could be found. The disappearance of the anti-Golgi complex antibody after stopping treatment and its absence in all other studied cases do suggest that it is related to the severe flares of ALT/GGT during treatment. An important contribution of this paper is that as documented histologically in one patient, this phenomenon was clearly associated with necro-inflammation and progressive fibrosis. This patient had a liver biopsy during the flare, and at the time of antiGolgi positivity, HCV-RNA was found to be negative. A second biopsy showed necro-inflammation and progression of fibrosis from $\mathrm{F} 2$ to $\mathrm{F} 3$ by METAVIR score in a blind analysis performed by two experimented pathologists. The explanation for this phenomenon remains a matter of speculation. Certainly, a transient autoimmune reaction must be considered. The presence of anti-Golgi complex antibody only during treatment and the coincident decrease of ALT after anti-Golgi complex antibody disappearance strongly argue in favor of this hypothesis. On the other hand, the Golgi complex is now recognized as an intracellular site for viral replication (15). Then, we could speculate that strong host system stimulation could have the Golgi complex as a target. In these cases, anti-Golgi complex antibody could be the result of its insult induced by specific antiviral response, while the 


\section{Anti-Golgi complex antibodies}

autoantibodies generated could be an epiphenomenon due to mere bystander collateral damage.

Against this hypothesis is the fact that none of the patients achieved sustained response. Although only three cases were studied, there is no evidence in favor of immunoclearance phenomena as described in hepatitis B flares during IFN treatment. The patient who had a liver biopsy during treatment showed histopathological features of progressive chronic liver disease and not a pattern of immunoclearance as lobular activity was not important (32).

Moreover, autoimmunity and extra-hepatic manifestations in hepatitis $\mathrm{C}$ infection are related to some impairment of the host's TH1 immune response generation (33). Such events are probably associated with less sustained virological response as observed in these three cases.

In conclusion, severe ALT/GGT flares during regulated IFN therapy for hepatitis $\mathrm{C}$ cannot always be considered a benign phenomenon. The presence of anti-Golgi complex antibody in these cases is intriguing, but suggests that it could be a marker of temporary autoimmune phenomena, associated with liver fibrosis progression.

This observation warrants further studies in order to define the incidence of this autoantibody during IFN plus ribavirin therapy, as well as its role as a pathogenic marker of a new PegIFN- $\alpha$ triggered autoimmune manifestation in hepatitis C.

\section{References}

1. Kim W R. Global epidemiology and burden of hepatitis C. Microbes Infect 2002; 4: 1219-25.

2. Alter M J, Kruszon-Moran D, Nainan O V, et al. The prevalence of hepatitis $\mathrm{C}$ virus infection in the United States, 1988 through 1994. N Engl J Med 1999; 341: 556-62.

3. Kenny-Walsh E. Clinical outcomes after hepatitis C infection from contaminated anti-D imune globulin. Irish Hepatology Research Group. N Engl J Med 1999; 340: 1228-33.

4. SeEFF L B. Natural history of chronic hepatitis C. Hepatology 2002; 36(Suppl. 1): S35-46.

5. Zinego A L, BRechot C. Extrahepatic manifestations of HCV infection: facts and controversies. J Hepatol 1999; 31: 369-76.

6. Clifford B D, Donahue D, Smith L, et al. High prevalence of serological markers of autoimmunity in patients chronic hepatitis C Hepatol, 1997; 26: 561-6 2002; 136: 747-57.

7. Herrine S K. Approach to the patient with chronic hepatitis C virus infection. Ann Intern Med 2002; 136: 747-57.

8. EASL International Consensus Conference on Hepatitis C. Consensus statements. J Hepatol 1999; 31: 3-8.

9. Luxon B A, Grace M, Brassard D, Bordens R. Pegylated interferon for the treatment of chronic hepatitis $\mathrm{C}$ infection. Clin Ther 2002; 24(9): 1363-83.

10. Herrmann E, Lee J H, Marnos G, Modi M, Zeuzem S. Effect of ribavirin on hepatitis $C$ viral kinetics in patients treated with pegylated Interferon. Hepatology 2002; 37: 1351-8.

11. Noda K, Enomoto N, Aria K, et al. Induction of antinuclear antibody after interferon therapy in patients with hepatitis type-C infection: its relation to the efficacy of therapy. Scand J Gastroenterol 1996; 41: 1672-7.

12. Di Cesare E, Previtti M, Russo F, et al. Interferon alfa therapy may induce insulin autoantibody development in patients with chronic viral hepatitis. Dig Dis Sci 1996; 41: 1672-7.

13. Rocca P, Codes L, Chevallier M, Trepo C, Zoulim F. Autoimmunization induced by interferon alpha therapy in chronic hepatitis C. Gastroenterol Clin Biol 2004; 28(11): 1173-6.

14. Parana R, Cruz M, Santos-Jesus R, Ferreira K, Codes L, Cruz T. Thyroid disease in HCV carriers undergoing antiviral therapy with interferon plus ribavirin. Braz J Infect Dis 2000; 4(6): 284-90.

15. Eibl N, Gschwantler M, Ferenci P, Eibl M M, Weiss W, Schernthaner G. Development of insulin-dependent diabetes mellitus in a patient with chronic hepatitis $\mathrm{C}$ during therapy with interferon-alpha. Eur J Gastroenterol Hepatol 2001; 13(3): 295-8.

16. Chutaputti A. Management of hepatitis C, adverse effects and other safety aspects of the hepatitis C antivirals. J Gastroenterol Hepatol 2000; 15: E156-63.

17. Manns M P, McHutchison J G, Gordon S C, et al. Pegintereferon alpha $2 \mathrm{~b}$ plus Ribavirin compared with interferon alpha $2 \mathrm{~b}$ plus ribavirin for initial treatment of chronic hepatitis C: a randomized trial. Lancet 2001; 358: 958-65.

18. Freid M W, Shiffmam M L, Reddy K R, et al. Peginterferon alpha2a (40Kd) plus Ribavirin for chronic hepatitis $\mathrm{C}$ virus infection. N Engl J Med 2002; 347: 975-82.

19. Russo M W, Fried M W. Side effects of therapy for chronic hepatitis C. Gastroenterology 2003; 124: 1711-9.

20. FrIEd M V. Side effects of therapy for hepatitis C and their management. Hepatology 2002; 36: S237-44.

21. Lo Re III V, Kostman J R. Management of chronic hepatitis C. Postgrad Med J 2005; 81: 376-89.

22. Deutsch M, Koshinas J, Tzannos K, et al. Hashimoto encephalopathy with pegylated interferon alfa- $2 \mathrm{~b}$ and ribavirin. Ann Pharmacother 2005; 39: 1745-7.

23. Rodriguez J L, Gelpi C, Thomson M, Real F L, FérNANDEZ J. Anti-Golgi complex autoantibodies in a patient with Sjogren syndrome and lymphoma. Clin Exp Immunol 1982; 49: 579-86.

24. Mohan T C, Jalil H A, Nadarajah M, Sng E H. Four patients in Singapore with anti-Golgi antibodies. Singapore Med J 1991; 32(5): 332-4.

25. Kladney R D, Cui X, Bulla G A, Brunt E M, Fimmel C J. Expression of GP73, a resident Golgi membrane protein, in viral and nonviral liver disease. Hepatology 2002; 35(6): 1431-40.

26. Mozo L, Simo A, Suarez A, Rodrigo L, Gutierrez C. Autoantibodies to Golgi proteins in hepatocellular carcinoma: case report and literature review. Eur J Gastroenterol Hepatol 2002; 14: 771-4.

27. Serafino A, Valli M B, Andreola F, et al. Suggested role of the Golgi apparatus and endoplasmic reticulum for crucial sites of hepatitis $\mathrm{C}$ virus replication in human lymphoblastoid cells infected in vitro. J Med Virol 2003; 70(1): 31-41.

28. Wong D K H, Cheung A M, O’Rourke K, Naylor C D, Detsky A S, HeathCote J. Effect of alpha-interferon treatment in patients with hepatitis $\mathrm{B}$ e antigen-positive chronic hepatitis B: a meta-analysis. Ann Intern Med 1993; 119: 312-23. 


\section{Paraná et al.}

29. Xu Z X, Hoffman J, Patel I. Single dose safety/tolerability and pharmacokinetic/pharmacodynamics (PK/PD) following administration of ascending subcutaneous doses of pegylated interferon (PEG-IFN) and interferon alfa-2a (INF alfa-2a) to healthy subjects. Hepatology 28Suppl.: 702A.

30. Venezia G, Licata A, Di Marco V, Craxi A, Almasio P L. Acute polymyositis during treatment of acute hepatitis C with pegylated interferon alpha-2b. Dig Liver Dis 2005; 37(11): 882-5.
31. Hurst E A, Mauro T. Sarcoidosis associated with pegylated interferon alfa and ribavirin treatment for chronic hepatitis C: a case report and review of the literature. Arch Dermatol 2005; 141(7): 865-8.

32. Chisari F V, Ferrari C. Hepatitis B virus immunopathology. Springer Sem Immunopathol 1995; 17: 26181.

33. Koziel M J. Immunology of viral hepatitis. Am J Med 1996; 100: 98-109. 